\title{
A diversidade de relacionamentos sexuais casuais e suas características
}

\author{
Maria-João Alvarez ${ }^{1}$, Marta Garcia ${ }^{1}$ \& Cícero R. Pereira ${ }^{2}$ \\ ${ }^{1}$ Faculdade de Psicologia, Universidade de Lisboa, CICPSI \\ 2 Universidade Federal da Paraíba, João Pessoa
}

\begin{abstract}
Resumo: Os relacionamentos sexuais casuais (RSC) são cada vez mais comuns, mas pouco se sabe sobre as principais formas e características desses envolvimentos no nosso país. Este estudo pretendeu contribuir para superar essa lacuna e recorreu a uma metodologia qualitativa para conhecer os RSC em que os adultos emergentes Portugueses se envolvem ( $N=177,18-30$ anos), e suas características. Realizaram-se três estudos, através de perguntas abertas recolhidas presencialmente e online, cujos resultados mostraram que um RSC se define pela ausência de envolvimento emocional e de compromisso e tem objectivos exclusivamente sexuais. Escalonamentos multidimensionais combinados com análise de clusters permitiram identificar quatro tipos principais de RSC: 'amigos coloridos', 'caso de uma noite', 'curte' e 'relacionamento casual'. Os quatro encontros mostraram-se diferentes entre si, distinguindo-se em 19 características. Conclui-se pela importância de abordar os mesmos como sendo distintos e com necessidades de intervenção diferentes no que se refere, nomeadamente, à protecção sexual.
\end{abstract}

Palavras-chave: Relacionamentos sexuais casuais; adultos emergentes; diversidade de relacionamentos; sexualidade.

The variety of casual sexual relationships and their characteristics: Casual sexual relationships (CSR) are increasingly common, but little is known about the main types and their characteristics in our country. This study sought to contribute to overcome this gap and made use of a qualitative methodology to learn about the CSR in which Portuguese emerging adults are involved ( $N=177,18-30$ years old). Three studies were carried out, using open questions collected in person and online, with results showing that a CSR is defined by the absence of emotional involvement and commitment and by having exclusively sexual objectives. Multidimensional scaling combined with cluster analysis enabled us to identify four types of CSR: friends with benefits, one-night stand, fooling around, and casual relationship. The four types of relationships show differences among themselves, distinguished by 19 characteristics. We conclude that making this differention is all the more important since the necessity of sexual protection may be perceived differently among them.

Keywords: Casual sexual relationships; emerging adults; relationship variety; sexuality.

No início deste século descreveram-se mudanças nas práticas relacionais entre estudantes universitários que apontavam para um declínio de encontros tradicionais e um aumento de encontros sexuais casuais (Glenn \& Marquardt, 2001; Paul, McManus, \& Hays, 2000). Investigações mais recentes confirmaram a normatividade da experiência nestes encontros entre jovens adultos emergentes (Armstrong, England, \& Fogarty, 2012; Kalish \& Kimmel, 2011) e na última revisão de literatura sobre a cultura hookup, observou-se que 60 a $80 \%$ dos estudantes universitários Norte Americanos esteve envolvido num relacionamento sexual casual (Garcia, Reiber, Massey, \& Merriwether, 2012). Em Portugal, os poucos estudos existentes sobre o tema apontavam para o envolvimento em encontros casuais por $1 / 3$ dos estudantes universitários (Alvarez, 2005; Reis, Ramiro, Gaspar de Matos, \& Diniz, 2012) e o mesmo se encontrou em jovens masculinos, entre os 18 e os 25 anos, sem frequência universitária (Carvalho, 2015). Estarão as relações sexuais casuais a ganhar maior importância na vida dos jovens adultos? Em caso afirmativo, estarão essas relações a tornar-se mais complexas e diversificadas? E se assim for, serão as características diferentes entre os vários encontros e terão em comum traços encontrados nos relacionamentos regulares? Estas são algumas das questões que norteiam o presente estudo.

Os relacionamentos sexuais casuais (RSC) são considerados habitualmente relacionamentos sexuais não comprometidos, fora do contexto de um relacionamento romântico, independentemente do tipo e extensão do conhecimento entre os indivíduos e da duração do relacionamento (Bersamin et al.,

${ }^{1}$ Morada de correspondência: Maria-João Alvarez, Faculdade de Psicologia, Universidade de Lisboa, Alameda da Universidade, $1649-013$ Lisboa. E-mail: mjalvarez@psicologia.ulisboa.pt 
2014). 0 compromisso pode ser definido como a intenção de persistir na manutenção de uma relação e os sentimentos de ligação psicológica ao outro ou we-ness (Rusbult, Martz, \& Agnew, 1998), manifestando-se na disponibilidade para se referir ao outro como "namorado/a" (Hamilton \& Armstrong, 2009). A satisfação e investimento na relação, as alternativas disponíveis, a confiança e a paixão sentida pelo(a) parceiro(a) são preditores do compromisso e são frequentemente utilizados na sua avaliação (Castañeda, 2000; Swan \& Thompson, 2016). Entendemos, por isso, um relacionamento sexual casual como um encontro presencial, habitualmente entre duas pessoas, que pode envolver diversas e diferentes manifestações sexuais, sem que haja claras expectativas mútuas de dar continuidade à interacção ou de envolvimento romântico e cuja duração e grau de conhecimento entre os indivíduos pode ser muito variável.

Uma diferença importante entre os RSC e os relacionamentos regulares diz respeito ao uso do preservativo, o qual diminui à medida que o relacionamento passa de novo/casual a regular e as explicações enfatizam o papel da longevidade do relacionamento no aumento da intimidade e confiança entre os parceiros (Macaluso, Demand, Artz, \& Hook, 2000; Misovich, Fisher, \& Fisher, 1997). Contudo, nos relacionamentos casuais metade dos indivíduos mostrou não utilizar preservativo (Reece et al., 2010) e estudos recentes identificaram relacionamentos sexuais casuais longos (Farvid \& Braun, 2017) com parceiros bem conhecidos, vividos por mais de metade dos adultos emergentes (e.g., Afifi \& Faulkner, 2000; Jonason, Li, \& Cason, 2009; Olmstead, Pasley, \& Fincham, 2017), não devendo pois a expressão ser tratada como um oxímoro. De facto, na investigação sobressaiu uma variedade de manifestações de intimidade emocional e sexual nos relacionamentos sexuais casuais, desde encontros sexuais que têm lugar uma só vez entre estranhos, a encontros continuados, mas impessoais e utilitários, até encontros sexuais que ocorrem entre amigos sem intenção de virem a tornar-se parceiros num relacionamento (Wentland, \& Reissing, 2011, 2014).

A possibilidade de os relacionamentos sexuais casuais combinarem características típicas dos relacionamentos regulares, como a longevidade e a familiaridade, tem relevância teórica para o estudo de novas formas de relacionamentos sexuais e consequências práticas pelo previsível efeito na percepção de menor necessidade de uso do preservativo e consequente risco sexual. Propomo-nos, por isso, conhecer os relacionamentos sexuais casuais em que os adultos emergentes portugueses se envolvem e as suas características, alicerçados na teoria dos guiões sexuais.

\section{Guiões e comportamento sexual}

Na perspectiva do interaccionismo simbólico é basilar a atribuição de significados semelhantes às acções pelos indivíduos, de modo a desenvolverem uma definição partilhada da situação que torne possível compreender a actividade conjunta em que se envolvem (Charon, 1995). Muito deste conhecimento é armazenado sob a forma de esquemas ou estruturas de conhecimento (Galambos, Abelson, \& Black, 1986) com um papel no processamento da informação social (Hastie, 1981). O conhecimento assim organizado permite o desenvolvimento de guiões, i.e., representações da sequência de acontecimentos esperados num determinado contexto, os quais facilitam as trocas do indivíduo com o meio pelas inferências e expectativas que possibilitam e pela orientação que fornecem para o próprio comportamento (Schank \& Abelson, 1977).

À semelhança do que ocorre para outros comportamentos sociais (e.g., Langer, 1978), desenvolvem-se guiões para o comportamento sexual (Gagnon, 1990; Maticka-Tyndale \& Herold, 1999). Estes são representações da sequência de acções estereotipadas associadas a encontros sexuais específicos e a sua organização ocorre através da abstracção de regularidades, seja através da experiência repetida com a situação, seja através das normas culturais e experiência vicariante (Schank \& Abelson, 1977). Alguns guiões sexuais foram objecto de investigação empírica e mostraram disponibilizar uma estrutura para compreender e antecipar o comportamento dos outros e influenciar as acções, incluindo as de protecção sexual, do indivíduo (Alvarez \& Garcia-Marques, 2008; Edgar \& Fitzpatrick, 1993; Mewhinney, Herold, \& Maticka-Tyndale, 1995).

A existência de conhecimento partilhado para uma diversidade de relacionamentos sexuais casuais (e.g., Wentland, \& Reissing, 2011, 2014) sugere a existência de guiões para estes encontros, cujo estudo está por realizar. Contudo, nem todos os relacionamentos sexuais casuais serão de igual qualidade para descrever, pensar e nomear os encontros sexuais, havendo razões para supor que estes encontros sofrem alterações de acordo com a cultura em que se inserem (Mervis \& Rosch, 1981). Deste modo, para que se possa vir a identificar os guiões que descrevem os RSC importa identificar primeiro os principais tipos de relacionamentos sexuais casuais existentes e as suas características, os quais se espera que resultem sobretudo de uma sensibilidade ao meio cultural onde se desenvolvem e não tanto de idiossincrasias das amostras. 


\section{O papel dos relacionamentos sexuais casuais}

Cada vez mais, em especial no mundo Ocidental, entre os 18 e os 30 anos as principais tarefas de vida passam por terminar os estudos, ser financeiramente independente e desenvolver uma carreira, que Hamilton e Armstrong (2009) designaram por imperativo de autodesenvolvimento. Casar e/ou formar uma família continuam a ser projectos, mas perspectivados num futuro longínquo.

Foram diversos os contributos para o aumento dos relacionamentos sexuais na Europa e nos Estados Unidos², desde as várias mudanças sociais com efeitos na dissolução de interdições sexuais, ao acesso a contraceptivos (e.g., Vilar, 2010), passando pela maior precocidade da puberdade, extensão da formação académica e adiamento do primeiro casamento e filho, bem como a importância atribuída à experiência sexual (e.g., Arnett, 2000). Também novas formas de viver os relacionamentos íntimos, nomeadamente através da vivência de relacionamentos não monogâmicos consensuais (Conley, Moors, Matsick, \& Ziegler, 2013) e a aceitação da legitimidade de múltiplos parceiros concomitantes, tanto por parte de homens como de mulheres (Ryan \& Jethá, 2010), podem constituir-se como razões acrescidas para o aumento dos relacionamentos sexuais nesta fase de vida.

Entre os principais motivos para o envolvimento em sexo casual descritos pelos próprios encontrou-se o preenchimento de hiatos entre relacionamentos comprometidos, a indisponibilidade de tempo para um relacionamento comprometido ou romântico devido a obrigações com o trabalho ou com os estudos, a grande mobilidade geográfica dos parceiros sexuais e considerar-se demasiado jovem para se "prender" a um relacionamento sério com tanto ainda para "ver e fazer" (Lyons et al., 2014). A ignorância pluralista, um conceito que reflecte sentir-se compelido a agir de acordo com a norma social percebida, apesar de partilhar crenças e atitudes pessoais discrepantes, pode constituir-se também como um factor contextual a considerar no aumento dos RSC, em especial no contexto da cultura universitária (Bogle, 2008; Allport, 1924 cit. por Lambert, Kahn, \& Apple, 2003).

Decorrente das tarefas de vida que se tornaram prioritárias, dos contextos sociais em que os jovens se movimentam e dos novos entendimentos sobre a vivência da sexualidade entre os parceiros, os RSC tornaram-se socialmente mais relevantes. As razões para o envolvimento nos RSC na actualidade ficam bem ilustradas nas categorias utilizadas por Aubrey e Smith (2013) para a construção de um índice de hookup, isto é, inofensividade, diversão, estatuto, controlo e liberdade sexual.

\section{A diversidade nos padrões de relacionamentos sexuais casuais}

Uma vez identificadas e descritas as mudanças nos relacionamentos sexuais nos últimos 50 anos, os investigadores passaram a interessar-se pelas diferentes formas que os RSC podiam tomar. Hookup é talvez a expressão mais utilizada para designar um RSC, e uma definição simples, à qual retirámos a heteronormatividade presente no original, descreve-o como um encontro em que duas pessoas se juntam para uma troca física e do qual não esperam mais nada (Glenn \& Masquardt, 2001). Devido à forma tão variável como foi definido, não se diferencia de outros RSC, pois tanto pode envolver apenas beijos como sexo penetrativo, ser limitado a uma noite ou mais prolongado e ocorrer entre desconhecidos ou amigos (ver Claxton \& Dulmen, 2013). Como tal, consideramos, à semelhança de outros autores, que se constitui mais como uma categoria abrangente para designar os vários tipos de RSC do que como um tipo de RSC (Heldman \& Wade, 2010). Talvez a expressão "engates" possa ilustrar o significado de hookup na língua inglesa.

Uma forma que os RSC podem tomar é designada por one night stand ou 'caso de uma noite' e caracteriza-se por um encontro de sexo entre dois estranhos ou pessoas que não se conhecem bem, sendo o contacto estabelecido habitualmente num contexto social (e.g., bar, festa), no qual um ou os dois estão sob a influência de álcool ou drogas. 0 encontro não é planeado, ocorre uma só vez, não havendo expectativa de que os intervenientes voltem a estar juntos, sendo por isso encontros com pouco envolvimento emocional (Singer et al., 2006; Wentland \& Reissing, 2011, 2014). Quando se dá continuidade a estes encontros a relação transforma-se e, no caso de os encontros se repetirem, ainda que esporadicamente, tornam-se em Booty Calls.

O Booty Call consiste num encontro sexual que ocorre de vez em quando com alguém que se conhece, combinado através de chamadas ou mensagens de texto, com a intenção urgente, dita ou implícita, de ter actividade sexual (Jonason et al., 2009; Nelson, Morrison-Beedy, Kearny, \& Dozier, 2011). Nalguns estudos encontra-se algum investimento e longevidade nestes encontros (Jonason, Li, \& Richardson, 2011), noutros, o investimento emocional é praticamente inexistente (Wentland \& Reissing, 2011). A atracção física é o motivo principal na origem destes encontros e ocorrem sobretudo para satisfação do desejo sexual, em especial nos homens (Jonason et al., 2009; Nelson et al., 2011). A

\footnotetext{
${ }^{2}$ Agradecemos a um revisor anónimo ter chamado a atenção para que nalguns países, como o Japão, se assistir a um aumento da proporção de homens e mulheres que nunca tiveram experiência sexual (Instituto Nacional da População e Segurança Social Japonês, 2017).
} 
imprevisibilidade e espontaneidade na forma como se iniciam e terminam estes relacionamentos constituem características definidoras destes encontros (Wentland \& Reissing, 2011, 2014). Quando a repetição se intensifica e os encontros se tornam mais frequentes, os encontros passam a ser designados por Fuck Buddies.

Os Fuck Buddy ou "parceiros de cama" dizem respeito a sexo entre duas pessoas que se conhecem e se encontram para ter relações sexuais regularmente. Podem tornar-se amigos na sequência da actividade sexual, não sendo a amizade prévia. Os indivíduos podem encontrar-se em actividades de natureza social, sendo que há sempre envolvimento em actividades sexuais. Habitualmente a relação de amizade não se mantém após deixar de haver actividade sexual (Wentland \& Reissing, 2011, 2014). Na literatura existem poucos estudos científicos sobre estes encontros.

Outros relacionamentos há que combinam a intimidade psicológica presente na amizade com a intimidade sexual, designados por Friends With Benefits e conhecidos por 'amigos coloridos'. Caracterizam-se por ser um relacionamento não romântico, entre dois amigos, que têm actividade sexual repetida ao longo do tempo, podendo ou não envolver-se em actividade sexual quando saem juntos (Claxton \& van Dulmen, 2013; Weaver, MacKeigan, \& MacDonald, 2011; Wentland \& Reissing, 2011). Um aspecto exclusivo destes encontros é o facto de os parceiros discutirem e negociarem entre si as regras do relacionamento. Parece ser importante haver esta discussão, de forma a garantir que os dois partilham do mesmo entendimento sobre o relacionamento e não têm expectativas diferentes sobre o seu desenrolar (Bisson \& Levine, 2009).

Pode concluir-se que existe investigação sobre as características dos encontros sexuais casuais e que estes se mostraram diversificados. Contudo, não só se detectaram algumas características com amplitudes bastante diferentes (e.g., intimidade sexual nos booty call, intimidade relacional entre amigos coloridos), como os RSC encontrados não foram os mesmos nos vários estudos (e.g., Jonason et al., 2009; Wentland \& Reissing, 2011). O papel facilitador dos ambientes para o comportamento sexual descrito por Bogle (2008) no seu livro sobre hooking up em estudantes universitários tinha já mostrado ser a sua averiguação muito relevante noutros contextos culturais. Concluímos, assim, sobre a existência de formas complexas de RSC que variam em diversas dimensões, a importância dos cenários culturais onde estes encontros se desenvolvem e a consequente pertinência do seu estudo em diferentes culturas.

\section{VISÃO GERAL DOS ESTUDOS}

Neste estudo averiguou-se como são definidos os relacionamentos sexuais casuais e efectuou-se um levantamento daqueles em que os adultos emergentes Portugueses se envolvem e/ou conhecem e as suas características. Para tal foram solicitadas definições sobre o que constituía um RSC e as designações utilizadas para os nomear e exploradas as características descritoras dos RSC mais distintivos. Desconhecemos a existência de estudos no nosso país que investiguem os relacionamentos sexuais casuais, ao qual acrescentamos uma primeira exploração das suas características.

Foram realizados três estudos qualitativos exploratórios. 0 primeiro teve como objectivo aceder aos relacionamentos casuais conhecidos/vividos e às dimensões em que estes se organizam. Para tal, solicitaram-se definições sobre o que constituía um RSC e as designações utilizadas para os nomear, no qual participaram 76 estudantes universitários. Analisadas as designações, houve necessidade de clarificar, num segundo estudo, com uma nova amostra constituída por 40 estudantes, alguns dos casos mais distintivos de entre os principais RSC encontrados no primeiro estudo. 0 objectivo deste segundo estudo foi o de ajudar a determinar o RSC mais distintivo quando o pólo da dimensão se mostrou constituído por mais de um relacionamento. Encontrados os quatro RSC mais distintivos, no terceiro estudo, com uma nova amostra com 61 estudantes universitários, foram aprofundadas as características descritoras de cada um destes RSC. Como o envolvimento prévio em RSC mostrou não diferenciar o conhecimento que os indivíduos têm das características dos diferentes encontros casuais (Wentland \& Reissing, 2014), contribuindo para se considerar conhecimento culturalmente adquirido, a experiência em RSC não constituiu condição para a participação nestes estudos.

Participaram no conjunto dos três estudos 177 participantes, 106 do género feminino (59.9\%), com idades compreendidas entre os 18 e os 30 anos $(M=21.95, D P=2.38)$, dos quais nove fizeram parte dos estudos piloto. A maioria dos participantes era solteira (96.7\%), disse não professar uma religião (58\%), tinha o Ensino Secundário (42\%) ou três anos de frequência do Ensino Superior (43\%) e 88\% indicou ter tido relações sexuais. Só 76 participantes (43\% do total da amostra) prestaram informação sobre o envolvimento num relacionamento sexual casual (apenas averiguado no Estudo 1). Destes, 39.4\% disse ter estado envolvido neste tipo de relacionamentos e a maioria dos encontros sexuais casuais teve como parceiro uma pessoa do outro sexo (82.2\%). A caracterização da amostra, por estudo, encontra-se na Tabela 1. 
Tabela 1. Características sociodemográficas da amostra por estudo

\begin{tabular}{|c|c|c|c|}
\hline \multirow[b]{2}{*}{ Características sociodemográficas } & \multicolumn{3}{|c|}{ Participantes (\%) } \\
\hline & $\begin{array}{c}\text { Estudo 1 } \\
(N=71)\end{array}$ & $\begin{array}{c}\text { Estudo } 2 \\
(N=40)\end{array}$ & $\begin{array}{c}\text { Estudo } 3 \\
(N=61)\end{array}$ \\
\hline \multicolumn{4}{|l|}{ Género } \\
\hline Masculino & $17(26.6)$ & $11(28.9)$ & $22(44.9)$ \\
\hline Feminino & $47(73.4)$ & $27(71.1)$ & $27(55.1)$ \\
\hline \multicolumn{4}{|l|}{ Estado Civil } \\
\hline Solteiro & $61(95.3)$ & 37 (97.4) & 47 (97.9) \\
\hline Casado & $1(1.6)$ & ---- & ---- \\
\hline União de facto & $2(3.1)$ & $1(2.6)$ & $1(2.1)$ \\
\hline \multicolumn{4}{|l|}{ Etnia } \\
\hline Caucasiana & $61(95.3)$ & $34(91.9)$ & $46(93.9)$ \\
\hline Africana & $1(1.6)$ & $2(5.4)$ & $1(2)$ \\
\hline Outra & $2(3.1)$ & $1(2.7)$ & $2(4.1)$ \\
\hline \multicolumn{4}{|l|}{ Professa Religião } \\
\hline Sim & 25 (39.7) & $17(44.7)$ & $21(42.9)$ \\
\hline Não & $38(60.3)$ & $21(55.3)$ & $28(57.1)$ \\
\hline \multicolumn{4}{|l|}{ Qual? } \\
\hline Católica & $24(96)$ & $16(76.2)$ & $20(95.2)$ \\
\hline Outra & $1(4)$ & $5(23.8)$ & $1(4.8)$ \\
\hline \multicolumn{4}{|l|}{ Habilitações Literárias } \\
\hline Ensino Secundário/12.ํa ano & $6(9.5)$ & $24(63.2)$ & $12(25)$ \\
\hline Até 3 anos de frequência de Ensino Superior ou Politécnico & $25(39.7)$ & $8(21)$ & $10(20.8)$ \\
\hline Curso Superior (4 ou mais anos curriculares) & 17 (27) & $4(10.5)$ & $15(31.3)$ \\
\hline Mestrado (incluindo mestrado integrado) & $15(23.8)$ & $2(5.3)$ & $11(22.9)$ \\
\hline \multicolumn{4}{|l|}{ Orientação sexual } \\
\hline Homossexual & $3(4.7)$ & $1(2.6)$ & $4(8.3)$ \\
\hline Bissexual & $9(14.1)$ & $3(7.9)$ & $2(4.2)$ \\
\hline Heterossexual & $52(81.2)$ & $33(86.9)$ & $41(85.4)$ \\
\hline Pansexual & --- & $1(2.6)$ & $1(2.1)$ \\
\hline
\end{tabular}

Os estudos foram aprovados pela Comissão de Ética da instituição portuguesa envolvida e os participantes foram solicitados a dar o seu consentimento informado

\section{ESTUDO 1}

\section{Participantes}

Fizeram parte do estudo 76 participantes (cinco dos quais do estudo piloto), 47 do género feminino (73.4\%), tendo os participantes idades compreendidas entre os 18 e os 30 anos $(M=22.16, D P=$ 2.18).

\section{Medidas}

Foram criadas cinco perguntas de resposta aberta para aceder à definição de cada participante sobre o que constituía um RSC e às designações conhecidas para os nomear. Primeiro solicitou-se uma definição de RSC, em seguida disponibilizou-se uma definição de RSC "no âmbito deste estudo, por relacionamento sexual casual entende-se um encontro entre duas pessoas (envolvendo beijos, carícias sexuais, sexo oral e/ou relações sexuais vaginais e/ou anais, entre outros) sem que haja claras expectativas mútuas de continuação da interacção ou de envolvimento romântico". Perguntou-se, depois, caso o participante já tivesse estado num RSC, que designações se atribuíam aos RSC em que tinha estado envolvido(a), indicando o género do(a) parceiro(a). Caso o participante nunca tivesse estado envolvido(a) num RSC, pediam-se as designações que conhecia para os nomear. Solicitou-se, ainda, aos participantes que já tinham estado envolvidos num RSC, que indicassem outras designações que conhecessem para 
além dos RSC em que tinham estado envolvidos. Foram ainda solicitados dados sociodemográficos (Ver Tabela 1).

\section{Procedimentos}

Realizou-se um estudo piloto com três participantes, presencialmente, para averiguar a compreensibilidade das perguntas, tendo sido alteradas algumas expressões para facilitar a sua compreensão, após o qual se realizou novo estudo piloto com outros dois participantes que revelou serem as perguntas totalmente compreensíveis. Os dados foram recolhidos presencialmente e online, o último através da plataforma Qualtrics com divulgação na rede social Facebook, durante sete dias, tendo 13 participantes realizado o preenchimento de forma presencial e 58 online.

\section{Procedimentos de análise}

Foi conduzida uma análise de conteúdo temática, organizada em categorias, prevista por Bardin (1977), de forma a detectar os principais temas que emergiram na definição de RSC cujo processo de construção foi indutivo e dedutivo. As respostas foram categorizadas com um valor de $-1,0,1$ ou 2 na respectiva categoria quando a definição envolvia a presença da característica (-1), a característica não era referida (0), a característica era explicitamente referida como estando ausente da definição (+1) (e.g., "não há envolvimento emocional") e a definição podia envolver quer a presença quer a ausência da característica (2). As respostas foram categorizadas por um dos autores e $10 \%$, obtido aleatoriamente através de um site de aleatorização, por dois dos autores. Da análise resultou um acordo entre juízes ${ }^{3}$ de $87 \%$, tendo sido discutidos os desacordos e obtido consenso.

Para a análise das designações atribuídas aos RSC (vivenciados ou conhecidos), estas foram agrupadas em categorias de forma a obter-se o menor número possível - mas respeitando a diversidade de respostas encontradas - e fez-se uma contagem de frequências.

Procedeu-se a uma análise multidimensional não paramétrica para fazer sobressair as dimensões em que as características das definições e as designações se organizaram. Os resultados foram confirmados recorrendo a uma análise de clusters. As análises foram realizadas com o SPSS, versão 25.

\section{Resultados}

Definição de relacionamento sexual casual. Obtiveram-se 71 respostas cuja análise resultou na organização de 10 categorias. As três categorias com maior frequência disseram respeito à ausência de envolvimento emocional e de compromisso e aos objectivos exclusivamente sexuais dos RSC (Tabela 2).

Tabela 2. Categorias definidoras dos relacionamentos sexuais casuais e respectiva frequência $(N=71)$

\begin{tabular}{lcccc}
\hline \multirow{2}{*}{ Categorias } & \multicolumn{3}{c}{ Participantes (\%) } \\
\cline { 2 - 4 } & Não refere & $\begin{array}{c}\text { Referido como } \\
\text { Ausente }\end{array}$ & Presente & $\begin{array}{c}\text { Ausente e } \\
\text { Presente }\end{array}$ \\
\hline Amizade & $66(93.0)$ & 0 & $2(2.8)$ & $3(4.2)$ \\
Compromisso & $41(57.7)$ & $29(40.8)$ & $1(1.4)$ & - \\
Decorrer na noite & $66(93.0)$ & - & $5(7.0)$ & - \\
Envolvimento emocional & $39(54.9)$ & $30(42.3)$ & - & $2(2.8)$ \\
Exclusividade & $65(91.5)$ & $5(7.0)$ & 0 & $1(1.4)$ \\
Intimidade & $66(93.0)$ & $3(4.2)$ & $2(2.8)$ & $2(2.2)$ \\
Nível de conhecimento & $65(91.5)$ & $3(4.2)$ & $26(36.6)$ & - \\
Objectivos exclusivamente sexuais & $45(63.4)$ & - & - & - \\
Premeditação & $66(93.0)$ & $5(7.0)$ & $9(12.7)$ & $6(8.5)$ \\
Repetição & $44(62.0)$ & $12(16.9)$ & & \\
\hline
\end{tabular}

A análise multidimensional realizada mostrou a presença de duas dimensões (Stress $=.004 ; \mathrm{R}^{2}=$ 99). A primeira dimensão contrapôs mais elevada satisfação sexual e envolvimento emocional a baixo compromisso. A segunda dimensão diferenciou o baixo compromisso de um conjunto de evocações cuja baixa variabilidade fez com que aparecessem agrupadas, sendo elas relações esporádicas, nível mais alto de conhecimento e de amizade, ocorrência nocturna, antecipado, mais elevada intimidade e exclusividade.

${ }^{3}$ Especialistas em comportamento sexual. 
A interpretação dessas dimensões foi, porém, inconclusiva. A análise de clusters agrupou as definições em três categorias, confirmando as proximidades verificadas na análise multidimensional (Fig. 1).

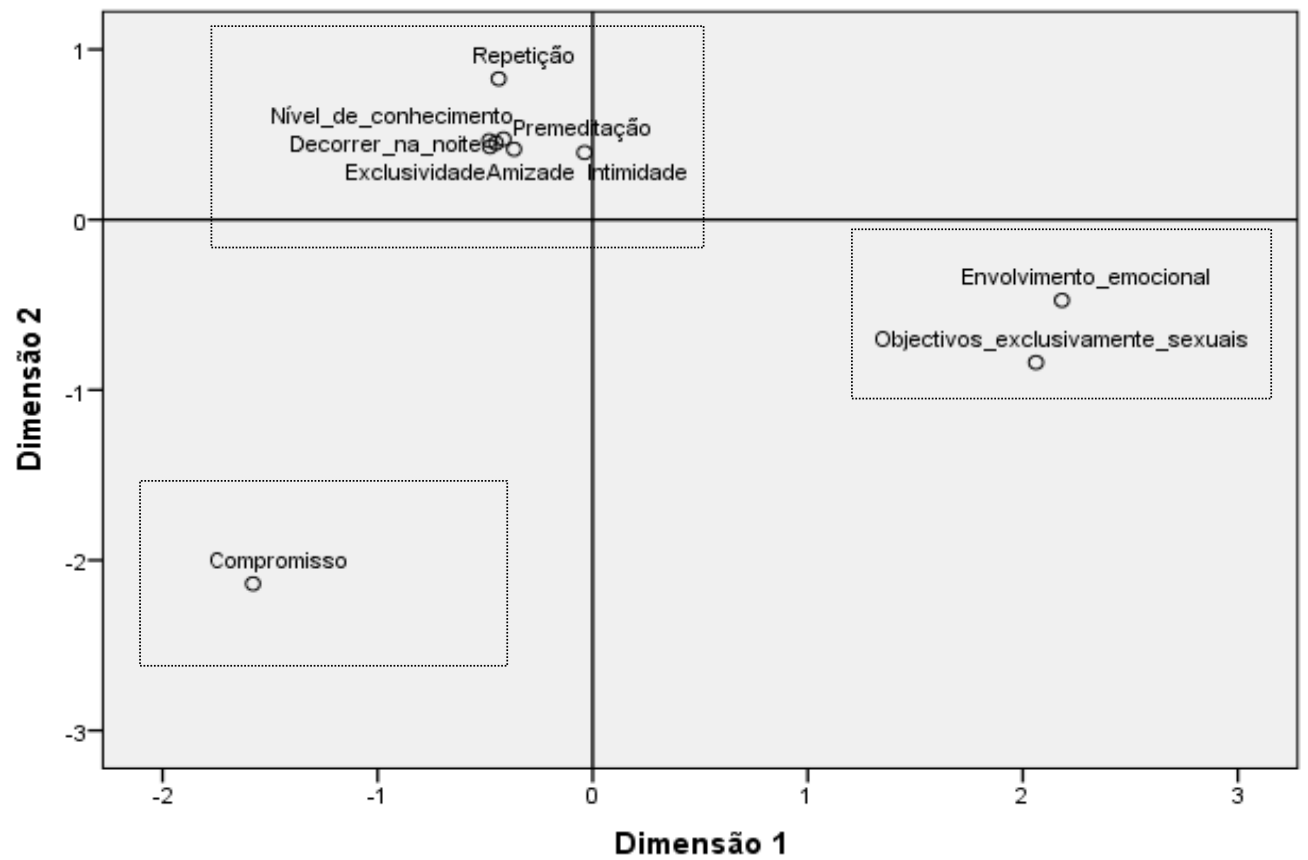

Figura 1. Representação gráfica da análise multidimensional e da análise de clusters das características dos relacionamentos.

De uma maneira geral, os RSC foram caracterizados como encontros nos quais se encontrou a primazia de objectivos exclusivamente sexuais associada à ausência de envolvimento emocional e de laços de compromisso. De facto, a representação gráfica da análise multidimensional situou o compromisso muito distante do envolvimento sexual sem envolvimento emocional.

Designações de relacionamentos sexuais casuais. Os RSC vividos ou conhecidos permitiram coligir um conjunto de designações, mais precisamente 25 designações $^{4}$, sendo que 14 foram referidas por mais de um participante, havendo quatro que foram utilizadas com maior frequência, a saber 'amigos coloridos', 'caso de uma noite', 'curte' e 'relação casual' (Tabela 3).

Tabela 3. Designações de relacionamentos sexuais casuais e respectiva frequência $(N=71)$

\begin{tabular}{lc}
\hline Designações & Participantes (\%) \\
\hline Amigos coloridos & $26(36.6)$ \\
Curte & $16(22.5)$ \\
Caso de uma noite & $13(18.3)$ \\
Relação casual & $13(18.3)$ \\
Fuck Buddy & $7(9.9)$ \\
Comilanço & $6(8.5)$ \\
Ir para a cama & $5(7.0)$ \\
Enrolanço & $4(5.6)$ \\
Booty calls & $3(4.2)$ \\
Cena & $3(4.2)$ \\
Dar uma volta & $3(4.2)$ \\
Paixão passageira & $3(4.2)$ \\
Beijos & $2(2.8)$ \\
Engate & $2(2.8)$ \\
\hline
\end{tabular}

${ }^{4}$ As seguintes designações foram referidas por um só participante: marmelada, voltar ao jogo, amor, caso perdido, explosivos, namoro, trio, tipos de sexo, carícias, encontro, passar a noite. 
A análise multidimensional realizada às designações referidas por mais de $5 \%$ dos participantes fez sobressair duas dimensões (Stress= .05; $\mathrm{R}^{2}=.99$ ). A primeira dimensão diferenciou 'amigos coloridos' de dois outros tipos de encontros, designados 'caso de uma noite' e 'curte'. A segunda dimensão diferenciou o encontro 'curte' de 'caso de uma noite' e 'relacionamento casual'. Os outros quatro tipos de relacionamento não apresentaram variabilidade suficiente para serem relevantes na definição das dimensões, pelo que se situaram juntos e muito próximos do centro da projecção bidimensional. Os resultados da análise de clusters classificaram as designações num cluster formado pelas designações com baixa variabilidade ('enrolanço', 'comilanço', 'fuck buddy' e 'ir para a cama') e os quatro exemplos de RSC, os quais apareceram isolados uns dos outros, o que denota terem sido percebidos como casos específicos e distintos de RSC (Fig. 2).

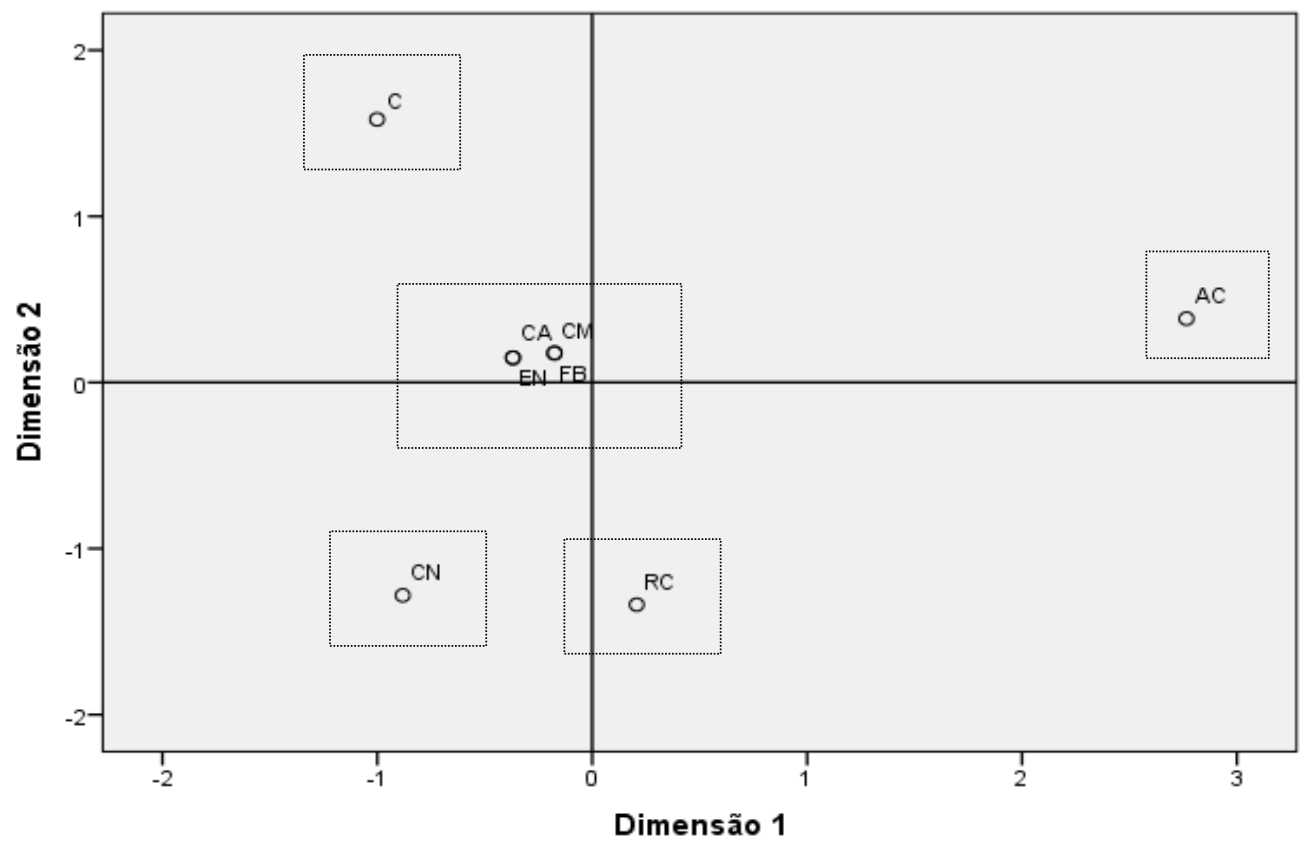

Figura 2. Representação gráfica da análise multidimensional e da análise de clusters das designações dos relacionamentos sexuais casuais (Nota. AC - Amigos coloridos; CN - Caso de uma noite; C - Curte; RC - Relacionamento casual; CM - Comilanço; EN - Enrolanço; FB - Fuck buddy; CA- Ir para a cama)

Em síntese, estes resultados mostraram que os participantes definiram como exemplos de RSC os 'amigos coloridos', diferenciando-os dos outros três tipos mais comuns: 'caso de uma noite', 'curte' e 'relacionamento casual'. Os 'casos de uma noite' parecem ser exemplares mais claros de relacionamentos sexuais casuais do que a 'curte', uma vez que apareceram no mesmo pólo do relacionamento casual na dimensão que os diferencia da 'curte'.

\section{ESTUDO 2}

A análise realizada às designações atribuídas aos RSC não permitiu decidir pelos encontros mais distintivos, uma vez que 'amigos coloridos' foi o encontro mais distintivo para um dos pólos da primeira dimensão, destacando-se no outro pólo dois encontros, 'caso de uma noite' e 'curte', não sendo claro qual o mais distintivo. Para a segunda dimensão, 'curte' foi o encontro mais distintivo de um dos seus pólos, sendo que o outro pólo foi constituído por dois encontros, 'caso de uma noite' e 'relação casual', não ficando claro o encontro que melhor descrevia o pólo oposto ao encontro ilustrado pela 'curte'. Deste modo, foi realizado um outro estudo para ajudar a determinar o caso mais distintivo dos pólos onde se encontraram mais de um encontro casual. Para tal, foram apresentadas as duas dimensões encontradas no Estudo 1 em que se organizaram os relacionamentos casuais e respectivos pólos e solicitado aos participantes que nomeassem as dimensões de acordo com a opinião e conhecimentos que detinham sobre RSC e seleccionassem o RSC mais típico quando existia mais de um relacionamento num dos pólos da dimensão. 


\section{Participantes}

Participaram neste estudo 40 participantes (dois do estudo piloto), 27 do género feminino (71.1\%), tendo os participantes idades compreendidas entre os 19 e os 29 anos $(M=21.13, D P=2.36)$.

\section{Medidas}

Para este estudo foram construídas duas tarefas para os encontros mais distintivos identificados no Estudo 1. Assim, foram apresentados aos participantes os encontros que formaram os dois pólos de cada dimensão (ver Fig. 2). Representando a dimensão 1 foram apresentados três RSC: 'amigos coloridos' (pólo 1) vs. 'casos de uma noite' e 'curte' (pólo 2). Representando a dimensão 2 foram apresentados os seguintes RSC: 'curte' (pólo 1) vs. 'caso de um noite' e 'relacionamento casual' (pólo 2). Na primeira tarefa solicitou-se ao participante que atribuísse um nome que desse significado à dimensão que descrevia os seus dois pólos de relacionamentos. Na segunda tarefa, pediu-se que observasse o pólo que apresentava dois RSC e escolhesse aquele relacionamento que melhor representava o pólo da dimensão. Foram ainda solicitados dados sociodemográficos (Ver Tabela 1).

\section{Procedimentos}

Os dados foram recolhidos presencial e individualmente, junto de uma amostra de conveniência. Cada conjunto foi constituído por três relacionamentos sexuais casuais que se dispuseram nos dois pólos de uma dimensão, um pólo contendo um relacionamento e o outro dois, de acordo com a análise multidimensional realizada no Estudo 1. Primeiramente, solicitou-se ao participante que atendesse aos dois pólos e referisse o que os distinguia. Pediu-se em seguida que, baseando-se nas diferenças encontradas, interpretasse e atribuísse uma designação à dimensão subjacente a esse conjunto de relacionamentos. Em seguida, pediu-se que observasse o pólo constituído pelos dois RSC e escolhesse aquele que melhor representava a dimensão atribuída (ver tarefa em Material Suplementar). Com esta tarefa obteve-se informação sobre a dimensão em que se organizavam os três relacionamentos e o relacionamento mais característico do pólo constituído por dois relacionamentos. As tarefas foram alvo de um estudo piloto prévio até que as perguntas realizadas não levantassem dúvidas.

\section{Procedimentos de análise}

Procedeu-se à análise da frequência de respostas das dimensões referidas para cada conjunto de relacionamentos, agrupando-se as dimensões de modo a criar o menor número de categorias, respeitando o sentido das respostas obtidas. Em seguida, de forma a analisar o relacionamento sexual casual mais distintivo de cada pólo da dimensão com mais de um relacionamento, foi feita uma contagem da frequência de respostas.

\section{Resultados}

Casos mais distintivos de relacionamentos sexuais casuais. A análise da frequência das respostas à questão sobre a nomeação de cada dimensão de relacionamentos permitiu conhecer o significado dos eixos que organizaram os dois pólos de cada dimensão na perspectiva dos participantes. Tomando em consideração os nomes dados às duas dimensões que obtiveram maior frequência, os encontros da dimensão 1 foram descritos como ilustrando o nível de conhecimento (16 respostas, 42.1\%) e a duração (12 respostas, $31.6 \%$ ) e os encontros da dimensão 2 foram descritos pela duração (12 respostas, 31.6\%) e pelo envolvimento emocional (6 respostas, $15.8 \%$ ).

A escolha do relacionamento mais representativo do pólo com dois relacionamentos que melhor representava a dimensão atribuída pelo participante, foi, para a dimensão 1 'caso de uma noite' e para a dimensão 2 'relacionamento casual' (Tabela 4).

Tabela 4. Relacionamento sexual casual seleccionado para o pólo constituído por dois relacionamentos na dimensão 1 e na dimensão $2(N=38)$

Pólos com Dois Relacionamentos Sexuais Casuais

Participantes (\%)

\begin{tabular}{ccccc}
\hline & Dimensão 1 & & \multicolumn{2}{c}{ Dimensão 2 } \\
\cline { 1 - 2 } Curte & Caso de uma noite & & Relacionamento casual & Caso de uma noite \\
$12(38.7)$ & $19(61.3)$ & & $21(63.6)$ & $12(36.4)$ \\
\hline
\end{tabular}

Nota. Para a dimensão 1 e 2 não se consideraram sete e cinco respostas, respectivamente. 
A síntese dos resultados dos dois primeiros estudos indicou-nos que os quatro relacionamentos sexuais casuais mais distintivos foram os 'amigos coloridos' (identificado no Estudo 1) e o 'caso de uma noite' para uma das dimensões; e a 'curte' (identificada no Estudo 1) e o 'relacionamento casual' para a outra dimensão como mostrou o Estudo 2. Neste estudo, a identificação dos casos foi possível articulando a dimensão atribuída a cada conjunto de encontros e os relacionamentos mais ilustrativos do pólo da dimensão constituído por dois encontros.

\section{ESTUDO 3}

Foi objectivo deste estudo aprofundar a identificação das características dos RSC. Para o efeito apresentaram-se aos participantes os quatro principais RSC identificados nos estudos anteriores, solicitando que referissem as principais características de cada um.

\section{Participantes}

Neste estudo estiverem envolvidos 61 participantes (dois do estudo piloto), sendo 27 do género feminino (55.1\%), tendo os participantes idades compreendidas entre os 18 e os 28 anos $(M=22.31, D P=$ 2.52).

\section{Medidas}

A medida envolveu uma pergunta na qual se solicitou ao participante que indicasse dez características descritivas para cada um dos quatro relacionamentos sexuais casuais apresentados. Foram ainda solicitados dados sociodemográficos (Ver Tabela 1).

\section{Procedimentos}

0 estudo piloto mostrou haver necessidade de alterar as instruções de forma a tornar mais compreensível a sua leitura. Neste estudo solicitou-se ao participante que indicasse dez características que descrevessem cada um dos RSC apresentados em conjuntos de dois encontros ('amigos coloridos' e 'caso de uma noite'; 'curte' e 'relacionamento casual'), seleccionados a partir dos encontros mais representativos de cada dimensão em que se organizaram as designações e do levantamento dos relacionamentos sexuais casuais mais distintivos de cada dimensão. Os dados foram recolhidos online, durante três semanas, através da plataforma Qualtrics, com divulgação na rede social Facebook.

\section{Procedimentos de análise}

Para cada relacionamento foram agrupadas as características referidas em categorias, procurando criar um número mínimo das mesmas, mas respeitando a diversidade encontrada e efectuada uma contagem de frequências a partir da presença/ausência das respostas a cada categoria. Esta categorização foi realizada pelas duas primeiras autoras. Para análise das diferenças entre os encontros, nas características referidas pelos participantes para os descrever, recorreu-se a um teste de Qui-quadrado uma vez terem-se classificado as características dos relacionamentos em duas categorias mutuamente exclusivas (presença $=1$; ausência $=0$ ). No caso de resultados significativos procedeu-se à análise dos resíduos estandardizados em cada célula para identificação das características mais evocadas e inibidas. Quando houve violação do pressuposto de menos de $20 \%$ de células com frequência esperada menor que 5, recorreu-se ao teste exacto de Fisher para verificação da robustez da significância dos resultados.

\section{Resultados}

Características dos casos mais distintivos de relacionamentos sexuais casuais. Obtiveram-se 836 respostas para os quatro encontros que se organizaram em 53 características. Na Tabela 5 apresentam-se as percentagens das 38 características descritas que obtiveram mais de três respostas, bem como a sua associação aos quatro tipos de encontros sexuais casuais como medido pelo Qui-quadrado e subsequente significância estatística. Foram 19 as características que mostraram diferenciar os encontros, tendo sido necessário recorrer ao teste de Fisher para 11 características, todas elas confirmadas. 
Tabela 5. Percentagem e Qui-quadrado das diferenças entre os encontros para cada característica $(N=$ 59)

\begin{tabular}{|c|c|c|c|c|c|c|}
\hline Características & $\begin{array}{c}\text { Amigos } \\
\text { coloridos }\end{array}$ & $\begin{array}{c}\text { Caso de uma } \\
\text { noite }\end{array}$ & Curte & $\begin{array}{c}\text { Relacionamento } \\
\text { casual }\end{array}$ & $X^{2}$ & Sig. \\
\hline Adolescência/Juventude & 12.5 & 25 & 62.5 & 0 & 7.25 & .06 \\
\hline Álcool/Drogas & 0 & 84.6 & 15.4 & 0 & 26.95 & $.00 * \mathrm{a}$ \\
\hline Amizade & 77.1 & 2.1 & 6.3 & 14.6 & 89.13 & $.00 *$ \\
\hline Aspectos negativos & 33.3 & 35.4 & 10.4 & 20.8 & 9.83 & $.02 *$ \\
\hline Atracção & 29.7 & 37.8 & 18.9 & 13.5 & 6.25 & .10 \\
\hline Beijos & 25 & 12.5 & 62.5 & 0 & 7.25 & .06 \\
\hline Agradável/Prazeroso/Diversão & 30.1 & 35.6 & 20.5 & 13.7 & 12.12 & $.01 *$ \\
\hline Compromisso & 22.2 & 0 & 0 & 77.8 & 15.13 & $.00 * \mathrm{*a}$ \\
\hline Confiança/Entrega & 62.1 & 10.3 & 6.9 & 20.7 & 25.59 & $.00^{*}$ \\
\hline Conhecidos & 36.4 & 27.3 & 9.1 & 27.3 & 1.81 & .61 \\
\hline Conhecidos ou desconhecidos & 0 & 50 & 25 & 25 & 2.03 & .57 \\
\hline Desconhecidos & 0 & 86.7 & 13.3 & 0 & 33.25 & $.00^{* a}$ \\
\hline Desejo & 18.8 & 56.3 & 6.3 & 18.8 & 9.66 & $.02 * a$ \\
\hline Envolvimento afectivo & 52.6 & 0 & 15.8 & 31.6 & 12.54 & $.01 * a$ \\
\hline Experiência & 20 & 40 & 40 & 0 & 2.25 & .52 \\
\hline Exploração & 21.4 & 14.3 & 35.7 & 28.6 & 1.52 & .69 \\
\hline Falar sobre a relação & 80 & 0 & 0 & 20 & 8.79 & $.03^{* a}$ \\
\hline Fuga & 0 & 25 & 25 & 50 & 2.03 & .57 \\
\hline Início de algo & 28.6 & 0 & 42.9 & 28.6 & 2.80 & .42 \\
\hline Instrumental & 37.5 & 25 & 25 & 12.5 & 1.04 & .79 \\
\hline Intimidade & 55.6 & 0 & 5.6 & 38.9 & 16.6 & $.00 * \mathrm{a}$ \\
\hline Namoro & 0 & 0 & 25 & 75 & 6.1 & .11 \\
\hline Não Exclusivo & 14.3 & 14.3 & 28.6 & 42.9 & 1.62 & .66 \\
\hline Não Premeditado & 17.9 & 38.5 & 15.4 & 28.2 & 6.24 & .10 \\
\hline Necessidade física/sexual & 20 & 60 & 20 & 0 & 3.88 & .27 \\
\hline Relação & 45.5 & 0 & 27.3 & 27.3 & 4.86 & .18 \\
\hline Relação não assumida & 66.7 & 8.3 & 0 & 25 & 13.35 & $.00^{* a}$ \\
\hline Relação sexual & 33.8 & 38 & 12.7 & 15.5 & 19.88 & $.00^{*}$ \\
\hline Repetido & 37.5 & 6.3 & 40.6 & 15.6 & 12.44 & $.01^{*}$ \\
\hline Respeito & 50 & 0 & 16.7 & 33.3 & 3.42 & .33 \\
\hline Romântico/Paixão & 55 & 5 & 15 & 25 & 12.24 & $.01^{*}$ \\
\hline Saída à noite & 0 & 72.7 & 27.3 & 0 & 16.31 & $.01^{* a}$ \\
\hline Segurança & 66.7 & 33.3 & 0 & 0 & 7.53 & .06 \\
\hline Sem compromisso & 40.5 & 21.6 & 23.0 & 14.9 & 15.51 & $.00^{* a}$ \\
\hline $\begin{array}{l}\text { Sem envolvimento } \\
\text { afectivo/romântico }\end{array}$ & 22.5 & 35 & 20 & 22.5 & 2.65 & .45 \\
\hline Sem envolvimento sexual & 0 & 0 & 100 & 0 & 12.21 & $.01^{* a}$ \\
\hline Sem ideia de futuro & 0 & 28.6 & 42.9 & 28.6 & 2.80 & .42 \\
\hline Uma só vez/Esporádico & 7.6 & 47 & 25.8 & 19.7 & 29.87 & $.00 *$ \\
\hline Total de características & 269 & 232 & 157 & 156 & & \\
\hline
\end{tabular}

Nota. As seguintes características foram referidas uma vez: afecto não recíproco, alter-ego, com ou sem amizade, com ou sem exclusividade, com ou sem repetição, locais específicos e rebelião; duas vezes: relação assumida, sem risco e valorização pessoal; três vezes: compensação, descomplicado, exclusivo, novas tecnologias, premeditado.

a resultados confirmados pelo Teste de Fisher. 
As análises dos resíduos mostraram ser a referência ao consumo de álcool/drogas maior no Caso de uma Noite (CN), tendo sido evocado aleatoriamente nos Amigos Coloridos (AC), na Curte (C) e no Relacionamento Casual (RC). A amizade caracterizou diferentemente os encontros, tendo-se mostrado uma componente significativa dos $\mathrm{AC}$, ausente do $\mathrm{CN}$ e da $\mathrm{C}$, ainda que essa ausência não tenha sido significativa em RC. Os aspectos negativos associados aos encontros caracterizaram a $\mathrm{C}$, estando mais presentes nos outros três encontros. Em relação à referência a características agradáveis nos encontros, RC mostrou-se menos agradável e divertido e uma relação caracterizada por maior compromisso do que o esperado. Houve maior referência à confiança no parceiro em $\mathrm{AC}$ e menos na $\mathrm{C}$, sendo aleatória a referência à confiança em $\mathrm{CN}$ e RC. $\mathrm{O}$ desconhecimento entre os parceiros mostrou ser mais referenciado no $\mathrm{CN}$ e menos em AC e RC. $\mathrm{O}$ envolvimento afectivo foi mais referido em AC do que seria de esperar de acordo com o acaso e menos referido do que o esperado em CN. Decorrer uma conversa sobre a relação mostrou-se uma componente significativa de AC, não sendo diferente do acaso nos demais encontros. No que concerne à existência de intimidade, esta mostrou-se significativa nos AC, estando ausente no CN. Não assumir o relacionamento caracterizou os AC e mostrou-se aleatório para os demais encontros. A existência de sexo caracterizou o CN e mostrou-se ausente na C, mostrando-se aleatória em AC e RC. A repetição caracterizou-se pela sua ausência no CN. O romantismo e a existência de paixão foram uma componente significativa de AC. Os encontros ocorrerem durante uma saída à noite mostrou ser um qualificativo do CN. A inexistência de compromisso caracterizou os AC, mostrou-se significativamente ausente no $\mathrm{CN}$ e RC e revelou-se aleatória em C. A ausência de envolvimento sexual mostrou ser uma componente significativa de $\mathrm{C}$, não se revelando significativa para qualquer um dos demais encontros. Por fim, o carácter esporádico do encontro caracterizou o CN e mostrou-se ausente nos AC.

\section{DISCUSSÃO}

Ao longo de três estudos foi possível conhecer as principais características de um RSC, identificar os RSC mais distintivos para adultos emergentes portugueses, bem como encontrar os atributos que melhor descrevem cada um destes encontros.

No que respeita à caracterização de um RSC, no qual 40\% da amostra disse já ter estado envolvida, este é descrito como um relacionamento sem envolvimento emocional, desprovido de expectativas de apegamento romântico e sem compromisso, que se sustém em objectivos exclusivamente sexuais, ainda que com diferentes níveis de conhecimento entre os parceiros e duração da interacção. Este entendimento vai ao encontro do que é descrito nos sites online com conselhos facultados por especialistas sobre como devem ser entendidos e vividos os relacionamentos sexuais casuais (Farvid \& Braun, 2013). Os resultados obtidos trazem um contributo importante à área dos relacionamentos sexuais casuais por corroborarem e expandirem as características veiculadas nestes sites. A descrição realizada pela amostra parece permitir aos jovens explorar e concretizar a sexualidade sem as responsabilidades e compromissos associados a um relacionamento mais sério, tal como já antes encontrado (Hamilton \& Armstrong, 2009; Shulman \& Connolly, 2013).

Foi possível verificar neste estudo que os encontros casuais não constituem um todo homogéneo, tal como antes a literatura mostrou acontecer entre relacionamentos regulares e casuais (Alvarez \& Garcia-Marques, 2008; Reece et al., 2010) e, mais recentemente, entre os próprios relacionamentos sexuais casuais (e.g., Claxton \& van Dulmen, 2013; Wentland \& Reissing, 2011, 2014), corroborando a multiplicidade de sentidos encontrada em estudos anteriores. Os quatro RSC identificados são ilustrativos desse fenómeno ao localizarem-se em pólos opostos no espaço bidimensional, a saber 'amigos coloridos' versus 'caso de uma noite'; e 'curte' versus 'relacionamento casual'. Os primeiros parecem diferenciar-se sobretudo no conhecimento existente entre os parceiros e na duração do relacionamento e os segundos na duração do relacionamento e no envolvimento emocional. Contudo, o estudo das dimensões em que se articulam os vários RSC não foi conclusivo. Os resultados da análise multidimensional e a dificuldade dos participantes em diferenciar alguns dos encontros no segundo estudo, aconselham cautela na identificação dos casos mais típicos, os quais, numa perspectiva mais conservadora, se podem circunscrever a dois, mais especificamente a 'amigos coloridos' e a 'caso de uma noite'.

Os quatro RSC diferenciaram-se em dezanove características. Entendemos o facto de os encontros se distinguirem em metade das características utilizadas para os descrever como mais um indicador de que os RSC se distinguem entre si e não devem ser considerados realidades homogéneas como têm sido habitualmente tratadas sob a designação genérica de "encontros casuais". Alguns dos atributos são menos associados à ideia que se tem de RSC, como a intimidade, o envolvimento afectivo e a repetição, enquanto outros vão mais ao encontro do que possa constituir um relacionamento sexual casual como o seu carácter esporádico, entre desconhecidos. À semelhança do encontrado na literatura (e.g., Claxton \& van Dulmen, 2013; Wentland \& Reissing, 2011), também na amostra em estudo se obtiveram atributos diferenciados para caracterizar os vários RSC, sendo alguns coincidentes com os utilizados para descrever 
um relacionamento regular. Estes resultados contribuem para a literatura ao ajudar a identificar as características distintivas em que se organizam os RSC.

Quanto à caracterização mais específica e articulada dos quatro principais RSC, houve uma maior referência à existência de confiança e ausência de compromisso nos amigos coloridos (AC) comparativamente aos outros relacionamentos. A maior confiança sentida entre AC deve-se seguramente a este relacionamento ocorrer entre duas pessoas que nutrem uma amizade prévia ao envolvimento sexual. Uma vez que a definição de RSC mostrou não envolver compromisso, seria de esperar que esta característica se mostrasse similar entre os diferentes encontros. Apesar disso, a ausência de compromisso foi especialmente enfatizada em AC, podendo tal dever-se ao facto de este tipo de relação envolver contornos mais dúbios devido à presença de amizade e de actividades sociais várias, sendo habitual haver uma conversa onde são definidas as "regras do relacionamento". A saliência da ausência de compromisso é particularmente importante nestes encontros para que nenhum dos intervenientes espere mais da relação (Bisson \& Levine, 2009) e esta não se confunda com um relacionamento regular. Uma das regras definidas foi também a da assunção ou não do relacionamento (Hughes, Morrison, \& Asada, 2005; Wentland \& Reissing, 2011), tendo sido esta característica referenciada mais vezes em AC. Com isto não se quer dizer que os restantes relacionamentos sejam assumidos, mas, ao invés, que nos $\mathrm{AC}$, - possivelmente por haver necessidade de esclarecer "as regras" da relação -, esta questão tenha de ser falada e discutida, como já encontrado nalguns estudos (Wentland \& Reissing, 2011), embora, noutros, os indivíduos (84\%) não discutam o relacionamento (Bisson \& Levine, 2009) nem o façam de forma directa (Weaver et al., 2011).

0 'caso de uma noite' diferenciou-se dos outros três relacionamentos por nele haver maior envolvido com álcool/drogas, o relacionamento acontecer entre desconhecidos, à noite, não haver envolvimento emocional e ocorrer uma só vez. São características habitualmente encontradas para este tipo de encontros e que lhe dão uma coerência clara (Wentland \& Reissing, 2014). Foram enfatizadas seis características em AC significativamente menos evocadas em CN, o que nos leva a dizer que estes dois encontros são os que mais se distinguem entre si. As características de AC e CN encontradas neste estudo vão ao encontro do descrito na literatura (Claxton \& van Dulmen, 2013; Jonason et al., 2011; Weaver et al., 2011; Wentland \& Reissing, 2011, 2014).

Uma 'curte' distinguiu-se por, neste tipo de relacionamento, existir uma maior referência a não ter de haver um envolvimento sexual. Como os RSC têm sobretudo um propósito sexual, esta ausência de envolvimento sexual poderá significar apenas a ausência de relações sexuais, havendo, no entanto, trocas físicas. De facto, é frequente na literatura descreverem-se relacionamentos casuais onde as trocas sexuais não envolvem penetração (e.g., Kuperberg \& Padgett, 2015), sendo neste estudo a 'curte' o encontro casual onde é mais habitual trocarem-se beijos e carícias, sem que ocorram práticas penetrativas entre os parceiros.

O relacionamento casual (RC) distinguiu-se por nele haver maior compromisso, característica que, a par de os parceiros não serem desconhecidos, parece apontar para um relacionamento mais estabelecido, mostrando haver nuances nas características definidoras de RSC. A 'curte' e o RC não estão entre os encontros mais frequentes encontrados nos estudos, ainda que se possa associar o primeiro a fooling around e o segundo a uma designação genérica de relacionamento casual. Assim sendo, ainda que sejam referidos na literatura, não obtêm a proeminência que foi encontrada no presente estudo realizado numa cultura diferente. É de salientar que a diferenciação destes dois últimos encontros foi uma tarefa difícil para os participantes, considerando-se que as diferenças entre estes relacionamentos poderão não ser muito claras.

Pode concluir-se que uma parte dos RSC mais distintivos para a amostra em estudo revelou características semelhantes às encontradas em estudos realizados noutras culturas anglo-saxónicas. Ainda assim, detectaram-se especificidades - como o destaque encontrado para a 'curte' - que não sabemos ainda se são particulares à amostra ou ilustrativas da vivência dos RSC no nosso país.

0 contributo mais inovador deste estudo decorre de ser o primeiro, com uma amostra portuguesa, a caracterizar de forma detalhada e qualitativa os RSC, mostrando a sua diversidade e deixando pistas para as dimensões psicológicas subjacentes. Como principais conclusões, este estudo mostra-nos que os RSC são relativamente frequentes entre os jovens adultos emergentes portugueses e possuem um conjunto de características que os definem, através do qual é possível para o indivíduo explorar a sua sexualidade sem estar envolvido num relacionamento exigente e de maior responsabilidade relacional. Esta possibilidade vai ao encontro do que é desejado e necessário ao adulto emergente nesta fase de vida, isto é, libertar recursos para o investimento profissional e académico, ao mesmo tempo que permite a interacção sexual sem comprometer a independência, tornando os RSC socialmente relevantes e normativos entre os jovens adultos. 
Contudo, os RSC não são todos iguais e embora possuam características genéricas, estas concretizam-se de forma particular e diferente em cada relacionamento e, nalguns casos, de forma oposta (e.g., ocorrer apenas uma vez ou ter um carácter repetido). É, assim, provável que os indivíduos tenham expectativas específicas sobre o seu comportamento e o do outro nos vários RSC e, consequentemente, haja um desenrolar de acontecimentos diferente para cada um dos RSC mais distintivos. Isto é, que os indivíduos possuam e utilizem guiões sexuais diferenciados. Este aspecto torna-se particularmente relevante se o foco for colocado na saúde sexual e, especificamente no uso de protecção sexual. Sendo a mobilização dos processos requeridos para este uso bastante dependente das características relacionais (Masters et al., 2015) e da interacção estabelecida, a diversidade de relacionamentos sexuais casuais vem reforçar a necessidade de se estudar esta protecção nestes diferentes contextos, bem como a sua inclusão/exclusão nos diversos guiões sexuais, com vista à prevenção do risco sexual.

Este estudo tem ainda implicações para a investigação, pois a mesma expressão remete para experiências de sexo casual bastante diferentes. Deste modo, devem definir-se de forma específica e clara os relacionamentos sexuais casuais que se pretendem estudar de forma a aumentar a validade externa dos estudos.

\section{LIMITAÇõES}

Encontram-se algumas limitações a esta investigação que importa considerar. Desde logo a condição de o estudo se basear num entendimento dos RSC como alternativas/opostos aos relacionamentos regulares, não se contemplando, nem estudando, relacionamentos íntimos românticos não exclusivos do ponto de vista emocional e/ou sexual consensualmente aceites pelos parceiros envolvidos, como relacionamentos poliamorosos ou relações abertas. Esta matriz pode, assim, deixar por explorar relacionamentos casuais com características diferentes das encontradas no presente estudo, ainda que o número de indivíduos envolvidos nestes relacionamentos seja relativamente baixo (Conley et al., 2013), em especial entre jovens adultos (ver Rubin, Moors, Matsick, Ziegler, \& Conley, 2014). Uma outra limitação prende-se com o facto de a amostra ser composta por um pouco mais de mulheres, e por a idade média dos participantes ser de 22 anos, isto é, abaixo do ponto médio da amplitude entre os 18 e os 29 anos que caracteriza os jovens adultos emergentes. Estes dois aspectos, a que acresce o facto de os participantes constituírem uma amostra de conveniência, implica que o conjunto de RSC mais distintivo tenha de ser encarado de forma cautelosa, ainda que em estudos qualitativos, como o que apresentamos, a ênfase incida nos significados subjectivos individuais em relação aos temas investigados. Uma outra limitação decorrente de se tratar de uma amostra com maior número de mulheres, prende-se com a possibilidade de as relações sexuais casuais estarem sub-reportadas caso a grande diferença encontrada nos estudos portugueses entre homens (57\%) e mulheres (22\%) (Reis et al., 2012) seja uma indicação do carácter anti-normativo destas experiências para as jovens adultas portuguesas. De facto, a existência de um duplo padrão na vivência destes relacionamentos nos campus universitários Norte Americanos foi descrita por Bogle (2008) e encontrada em estudos mais recentes na cultura portuguesa (Amaro, Alvarez, \& Ferreira, submetido). Consideramos, igualmente, uma limitação a este estudo o entendimento das características atribuídas aos encontros como categoriais, ao invés de poderem espelhar gradações de diferentes graus da característica. Outra limitação a salientar diz respeito à ausência de contrabalanceamento dos encontros no terceiro estudo, o que pode ter contribuído para que o número de características produzido possa ter resultado da ordem de apresentação da tarefa e não das características dos próprios encontros. Ainda relativamente ao terceiro estudo, não foi possível compreender o sentido de alguns atributos, uma vez que não foi solicitado um esclarecimento das características apresentadas.

Em investigações futuras será importante desenvolver as características que descrevem os diferentes relacionamentos em entrevistas com grupos focais, pois estas permitem esclarecer e aprofundar o sentido que lhes é atribuído na descrição dos encontros e vir a desenvolver os guiões sexuais associados a cada RSC. O encontro designado por relacionamento casual pode tratar-se de uma redundância que importa em futuros estudos averiguar. Será igualmente relevante que em estudos futuros se investigue a existência de diferenças na categorização dos encontros entre mulheres e homens.

\section{CONCLUSÕES}

Concluímos, a partir deste estudo, que o envolvimento em RSC se mostra relativamente frequente e reflecte o carácter normativo destes relacionamentos, tal como encontrado no início deste século noutras culturas. Ainda assim, alguns dos principais RSC são diferentes dos encontrados em estudos anteriores, mostrando variar em função da cultura em que se desenvolvem. Concluímos, igualmente, existir conhecimento socialmente partilhado sobre os principais RSC e uma diferenciação considerável entre os seus atributos. Daqui decorre a provável existência de guiões sexuais diferentes para os vários RSC 
identificados, o que implica que estes relacionamentos poderão desenrolar-se de forma diferente e comportar percepções igualmente diferentes quanto à necessidade de uso de preservativo. Se assim for, com vista à prevenção do risco sexual, deverão ser desenvolvidas intervenções adaptadas a cada realidade relacional, sendo esta diferenciação tanto mais importante quanto se detectaram características típicas de um relacionamento regular associadas a alguns dos RSC. Referimo-nos a um elevado nível de amizade, compromisso, conhecimento entre os parceiros, intimidade e confiança, características que estão associadas a um decréscimo no uso do preservativo (Misovich et al., 1997). 0 conhecimento dos RSC mais distintivos e das suas características poderá, assim, contribuir para o desenvolvimento de intervenções no âmbito da protecção sexual mais adaptadas aos diferentes encontros e sensíveis às diferenças entre eles.

\section{REFERÊNCIAS}

Afifi, W. A., \& Faulkner, S. L. (2000). On being 'just friends': The frequency and impact of sexual activity in cross-sex friendships. Journal of Social and Personal Relationships, 17, 205-222.

Alvarez, M.-J. (2005). Representações cognitivas e comportamentos sexuais de risco: O guião e as teorias implícitas da personalidade nos comportamentos de protecção sexual. Lisboa FCT/FCG.

Alvarez, M.-J., \& Garcia-Marques, L (2008). Condom inclusion in cognitive representations of sexual encounters. Journal of Sex Research, 45, 358-370.

Amaro, H., Alvarez, M.-J., \& Ferreira, J. A. (submetido). College students' perceptions about the Social Sexual Double Standard: Developing a comprehensive model for Social SDS.

Armstrong, E. A., England, P., \& Fogarty, A. C. (2012). Accounting for women's orgasm and sexual enjoyment in college hookups and relationships. American Sociological Review, 77, 435-462.

Arnett, J. J. (2000). Emerging adulthood: A theory of development from the late teens through the twenties. American Psychologist, 55, 469-480.

Aubrey, J., \& Smith, S. (2013). Development and validation of the endorsement of the Hookup Culture Index. Journal of Sex Research, 50, 435-448.

Bardin L. L. (1977). L'analyse de contenu. Paris: Presses Universitaires de France.

Bersamin, M., Zamboanga, B., Schwartz, S., Donnellan, M., Hudson, M., Weisskirch, R.,... Caraway, S. (2014). Risky business: Is there an association between casual sex and mental health among emerging adults? Journal of Sex Research, 51, 43-51.

Bisson, M.A., \& Levine, T.T. (2009). Negotiating a friends with benefits relationship. Archives of Sexual Behavior, 38, 66-73.

Bogle, L. (2008). Hooking up: Sex, dating, and relationships on campus. N.Y.: New York University Press.

Carvalho, T. (2015). Condom use among heterosexual young men: An examination of volitional predictors and a stage-based intervention. Lisboa: Tese de doutoramento apresentada à Universidade de Lisboa.

Castañeda, D. (2000). The close relationships context of HIV/AIDS risk reduction among Mexican Americans. Sex Roles, 42, 551-580.

Charon, J. (1995). Symbolic interactionism: An introduction, interpretation, and integration (5 $5^{\text {th }}$ ed.). Englewood Cliffs, N.J.: Prentice-Hall.

Claxton, S., \& van Dulmen, M. (2013). Casual sexual relationships and experiences in emerging adulthood. Emerging Adulthood, 1, 138-150.

Conley, T., Moors, A., Matsick, J., \& Ziegler, A. (2013). The fewer the merrier?: Assessing stigma surrounding consensually non-monogamous romantic relationships. Analyses of Social Issues and Public Policy, 13, 1-30.

Edgar, T., \& Fitzpatrick, M. (1993). Expectations for sexual interaction: A cognitive test of the sequencing of sexual communication behavior. Health Communication, 5, 239-261.

Farvid, P., \& Braun, V. (2013). Casual sex as "not a natural act" and other regimes of truth about heterosexuality. Feminism and Psychology, 23, 359-378.

Farvid, P., \& Braun, V. (2017). Unpacking the "pleasures" and "pains" of heterosexual casual sex: Beyond singular understandings. Journal of Sex Research, 54, 73-90.

Gagnon, J. (1990). The explicit and implicit use of scripting perspective in sex research. Annual Review of Sex Research, 1, 1-43.

Galambos, J., Abelson, R., \& Black, J. (1986). Knowledge structures. Hillsdale, N.J.: Lawrence Erlbaum Assoc.

Garcia, J., Reiber, C., Massey, S., \& Merriwether, A. (2012). Sexual hookup culture: A review. Review of General Psychology, 16, 161-176.

Glenn, N., \& Marquardt, E. (2001). Hooking up, hanging out and hoping for mister right: College women on dating and mating today. NY: Institute for American values report to the independent women's forum. 
Hamilton, L., \& Armstrong, E. (2009). Gender sexuality in young adulthood: Double binds and flawed options. Gender \& Society, 23, 589-616.

Hastie, R. (1981). Schematic principles in human memory. In E. Higgins, C. Herman, \& M. Zanna (Eds.), Social cognition: The Ontario symposium on personality and social psychology, (Vol.1, pp. 39-88). Hillsdale, N.J.: Lawrence Erlbaum Assoc.

Heldman, C., \& Wade, L. (2010). Hook-up culture: Setting a new research agenda. Sex Research and Social Policy, 7, 323-333.

Hughes, M., Morrison, K., \& Asada, K., L. (2005) What's love got to do with it? Exploring the impact of maintenance rules, love attitudes, and network support on friends with benefits relationships. Western Journal of Communication, 69, 49-66.

Instituto Nacional da População e Segurança Social Japonês (2017). The fifteenth Japanese National Fertility Survey in 2015. Marriage process and fertility of married couples, attitudes toward marriage and family among Japanese singles: Highlights of the survey results on married couples/singles.

Jonason, P. K., Li, N. P., \& Cason, M. J. (2009). The “booty call”: A compromise betwen men's and women's ideal mating strategies. Journal of Sex Research, 46, 460-470.

Jonason, P. K., Li, N. P., \& Richardson, J. (2011). Positioning the booty-call relationship on the spectrum of relationships: Sexual but more emotional than one-night stand. Journal of Sex Research, 48, 486495.

Kalish, R., \& Kimmel, M. (2011). Hooking up: Hot hetero sex or the new numb normative? Australian Feminist Studies, 26, 137-151.

Kuperberg, A., \& Padgett, J. (2015). Dating and hooking up in college: Meeting contexts, sex, and variation by gender, partner's gender, and class standing. Journal of Sex Research, 52, 517-531.

Lambert, T., Kahn, A., \& Apple, K. (2003). Pluralistic ignorance and hooking up. Journal of Sex Research, 40, 129-133.

Langer, E. (1978). Rethinking the role of thought in social interaction. In J. Harvey, W. Ickes, \& R. Kidd (Eds.), New directions in attribution research, (Vol. 2, pp. 35-58). Hillsdale, N.J.: Lawrence Erlbaum Assoc.

Lyons, H., Manning, W., Longmore, M., \& Giordano, P. (2014). Young adult casual sexual behavior lifecourse-specific motivations and consequences. Sociological Perspectives, 57(1), 79-101.

Macaluso, M., Demand, M., Artz, L., \& Hook, E. (2000). Partner type and condom use. AIDS, 14, 537-546.

Masters, T., Casey, E., Beadnell, B., Morrison, D., Hoppe, M., \& Wells, E. (2015). Condoms and contexts: Profiles of sexual risk and safety among young heterosexually active men. Journal of Sex Research, 52, 781-794.

Maticka-Tyndale, E., \& Herold, E. (1999). Condom use on spring-break vacation: The influence of interventions, prior use, and context. Journal of Applied Social Psychology, 29, 1010-1027.

Mervis, C., \& Rosch, E. (1981). Categorization of natural objects. Annual Review of Psychology, 32, 89-115.

Mewhinney, D., Herold, E., \& Maticka-Tyndale, E. (1995). Sexual scripts and risk-taking of Canadian university students on spring break in Daytona beach, Florida. The Canadian Journal of Human Sexuality, 4, 273-288.

Misovich, S., Fisher, J., \& Fisher, W. (1997). Close relationships and elevated HIV risk behavior evidence and possible underlying psychological processes. Review of General Psychology, 1, 72-107.

Nelson, L. E., Morrison-Beedy, D., Kearney, M., H., \& Dozier, A. (2011). Sexual partner type taxonomy use among urban black adolescent mothers in the United States. The Canadian Journal of Human Sexuality, 20(1-2), 1-10.

Olmstead, S. P., Pasley, K., \& Fincham, F. (2017). College men's involvement in friends with benefits relationships. College Student Journal, 50, 398-403.

Paul, E., McManus, B., \& Hayes, A. (2000). "Hookups": Characteristics and correlates of college students' spontaneous and anonymous sexual experiences. Journal of Sex Research, 37, 76-88.

Reis, M., Ramiro, L., Gaspar de Matos, M., \& Diniz, J. (2012). Os comportamentos sexuais dos universitários portugueses de ambos os sexos em 2010. Revista Portuguesa de Saúde Pública, 30, 105-114.

Reece, M., Herbenick, D., Cchick, V., Sanders, S., Dodge, B., \& Fortenberry, D. (2010). Condom use rates in a national probability sample of males and females ages 14 to 94 in the United States. Journal of Sexual Medicine, 7(suppl 5), 266-276.

Rubin, J., Moors, A., Matsick, J., Ziegler, A., \& Conley, T. (2014). On the margins: Considering diversity among consensually non-monogamous relationships. Journal fur Psychologie, 22(1), 19-37.

Rusbult, C., Martz, J., \& Agnew, C. (1998). The Investment Model Scale: Measuring commitment level, satisfaction level, quality of alternatives, and investment size. Personal Relationships, 5, 357-391.

Ryan, C., \& Jethá, C. (2010). Sex at dawn: How we mate, why we stray, and what it means for modern relationships. N.Y.: Harper Perennial. 
Schank, R., \& Abelson, R. (1977). Scripts, plans, goals, and understanding. Hillsdale, N.J.: Lawrence Erlbaum Assoc.

Shulman, S., \& Connolly, J. (2013). The challenge of romantic relationships in emerging adulthood: Reconceptualization of the field. Emerging Adulthood, 1(1), 27-39.

Singer, M., Erikson, P., Badiane, L., Diaz, R., Ortiz, D., Abraham, T., \& Nicolaysen, A. (2006). Syndemics, sex, and the city: Understanding sexually transmitted diseases in social and cultural context. Social Science \& Medicine, 63, 2010-2021.

Swan, D., \& Thompson, S. (2016). Monogamy, the protective fallacy: Sexual versus emotional exclusivity and the implication for sexual health risk. Journal of Sex Research, 53, 64-73.

Vilar, D. (2010). Contracepção e aborto na paisagem conjugal e sexual contemporânea. In P. M. Ferreira \& M. Villaverde Cabral (Org.), Sexualidades em Portugal: Comportamentos e riscos (pp. 289-321). Lisboa: Bizâncio.

Weaver, A. D., MacKeigan, K. L., \& MacDonald, H. A. (2011). Experiences and perceptions of young adults in friends with benefits relationships: A qualitative study. Canadian Journal of Human Sexuality, 20(1-2), 41-53.

Wentland, J., \& Reissing, E. (2011). Taking casual sex not too casually: Exploring definitions of casual sexual relationships. Canadian Journal of Human Sexuality, 20(3), 75-91.

Wentland, J., \& Reissing, E. (2014). Identifying definitions for one night stands, booty calls, fuck buddies, and friends with benefits. Canadian Journal of Human Sexuality, 23(3), 23-40.

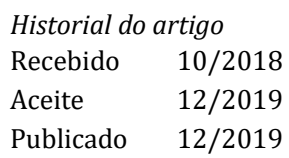

Aceite $\quad 12 / 2019$

Publicado 12/2019

\section{MATERIAL SUPLEMENTAR}

Apresentam-se em seguida dois conjuntos de tipos de relacionamentos sexuais casuais dispostos em dois pólos opostos. A tarefa que lhe pedimos consiste em atribuir, a cada conjunto, uma dimensão que descreva o que varia entre os dois pólos. É-lhe pedido ainda que, analisando a dimensão que atribuiu ao conjunto, e o pólo que apresenta dois tipos de relacionamentos sexuais, escolha aquele que melhor representa a dimensão por si atribuída.

\section{Conjunto 1}

Caso de uma noite

Amigos Coloridos

Curte

Dimensão:

No pólo constituído por dois relacionamentos casuais (à esquerda) qual o relacionamento mais representativo ou que melhor ilustra a dimensão:

\section{Conjunto 2}

Relacionamento Casual

Curte

Caso de uma noite

Dimensão:

No pólo constituído por dois relacionamentos casuais (à esquerda) qual o relacionamento mais representativo ou que melhor ilustra a dimensão: 
A diversidade de relacionamentos sexuais casuais 